\title{
Desminado humanitario en los escenarios coyunturales del posconflicto colombiano: una mirada jurídico-política
}

\author{
Diana Patricia Arias* \\ Juanita María Ospina Perdomo**
}

Artículo recibido: $1^{\circ}$ de octubre de 2017

Artículo aprobado: 18 de julio de 2018

Doi: https://doi.org/10.12804/revistas.urosario.edu.co/desafios/a.6389

Para citar este artículo: Arias, D. P. \& Ospina Perdomo, J. M. (2020). Desminado humanitario en los escenarios coyunturales del posconflicto colombiano: una mirada jurídico-política. Desafíos, 32(1), 1-39. https://doi.org/10.12804/revistas.urosario.edu.co/desafios/a.6389

\section{Resumen}

El artículo, mediante una metodología analítica, hace una aproximación teórica de derecho internacional contemporáneo sobre los aspectos jurídicos y politicos relativos al diseño, implementación y gestión del Programa Piloto de Desminado Humanitario (DH) entre las FARC y el gobierno colombiano durante 2016. Para este propósito, se recurre a fuentes primarias y secundarias, tradicionales, asi como a entrevistas semiestructuradas realizadas a informantes clave; también, a resultados ofrecidos por el uso de la técnica web mining durante el recorte temporal descrito respecto a elementos jurisprudenciales y doctrinales. Se ratifica un escenario de subsidiariedad penal erga omnes frente al uso de artefactos explosivos enterrados y se demuestra que

* Docente de tiempo completo de la Facultad de Relaciones Internacionales, Estrategia y Seguridad de la Universidad Militar Nueva Granada. Correo electrónico: diana.arias@, unimilitar.edu.co. ORCID: http://orcid.org/0000-0002-4289-5186

** Doctoranda en Ciencias Jurídicas de la Universidad de Granada (España). Correo electrónico: juanitaospina@yahoo.com. ORCID: https://orcid.org/0000-0003-3078-948X 


\title{
2 I Diana Patricia Arias - Juanita María Ospina Perdomo
}

esta práctica, generalizada en el conflicto armado interno colombiano, no es más que una lección de estrategia aprendida de las acciones militares engendradas en las guerras mundiales y el derecho internacional clásico.

Palabras clave: posconflicto, desminado bumanitario, jurisprudencia, Colombia.

\section{Humanitarian Demining in the Colombian Post- Conflict Period: A Legal-Political Perspective}

\begin{abstract}
This article makes a theoretical approach via an analytical methodology to study contemporary international legal and political aspects of the design, implementation, and management of the Humanitarian Demining Pilot Program (DH) agreed in 2016 between FARC and the Colombian government. We analyze the jurisprudential and doctrinal elements and describe a scenario of criminal subsidiarity erga omnes against the use of buried explosive devices through primary and secondary traditional sources, semi-structured interviews carried out with key informants, and the results offered by the use of the web mining techniques during the analyzed period. We demonstrate that this practice, widespread in Colombia's internal armed conflict, is nothing more than a strategy derived from military experiences made in World War I and II, and from classical international law.
\end{abstract}

Keywords: Post-conflict, bumanitarian demining, case law, Colombia.

\section{Desminagem humanitária nos cenários conjunturais do pós-conflito colombiano: um olhar jurídico-político}

\begin{abstract}
Resumo
$O$ artigo, através de uma metodologia analitica, realiza uma aproximação teórica de direito internacional contemporâneo, sobre os aspectos jurídicos e políticos relativos ao desenho, implementação e gestão do Programa Piloto de Desminagem Humanitária (DH) entre as FARC e o governo Colombiano, durante 2016. Para este propósito, recorre-se a fontes primárias e secundárias, tradicionais, assim como entrevistas semiestruturadas
\end{abstract}


realizadas a informantes chave; também, a resultados oferecidos pelo uso da técnica web mining durante o recorte temporal descrito, a respeito de elementos jurisprudenciais e doutrinais. Ratifica-se um cenário de subsidiariedade penal erga omnes frente ao uso de artefatos explosivos enterrado e demostra-se que esta prática, generalizada no conflito armado interno colombiano, não é mais do que uma lição de estratégia aprendida das ações militares engendradas nas Guerras Mundiais e o direito internacional clássico. Palavras-chave: pós-conflito, desminagem humanitária, jurisprudência, Colômbia.

\section{Introducción}

Podemos ubicar el concepto teórico de posconflicto en el inicio de la escena contemporánea del derecho internacional público (DIP), bajo nuevos esquemas de justicia penal alternativa denominados justicia transicional e implementados en los controvertidos tribunales ad hoc de Núremberg y Tokio, que parte en dos la normativa jurídica internacional y cambia, drásticamente, los paradigmas juridicistas del sistema internacional: 1) derecho internacional clásico o escuela relacional y 2) derecho internacional público contemporáneo o escuela institucional, vigente en la actualidad global. La escuela relacional se caracterizó por un único sujeto con personalidad jurídica internacional: los Estados clásicos, conformados por cuatro elementos soberanos: población, territorio, poder político y reconocimiento internacional constitutivo y bilateral. Adicionalmente, el uso de la violencia estatal estaba legitimado para resolver conflictos internacionales y el vencedor poseía los territorios vencidos, multiplicando las respectivas catástrofes humanas.

La ley de la fuerza armada se conceptualizó tradicionalmente en las categorías de jus ad bellum y jus in bello. Concepción dualista del período de entreguerras, que provocó la interconexión conceptual entre intervención, conflicto armado y construcción de paz; concepción tripartita de la fuerza armada, incluido el concepto de justicia después de la guerra ( jus post bellum), que tiene larga tradición en la filosofía moral y la teoría jurídica. Sin embargo, desde una perspectiva legal, las reglas contemporáneas de jus ad bellum y jus in bello, cada vez más, tienden hacia la seguridad humana, identificando reglas y principios legales que subyacen a una concepción moderna de just post bellum (Stahn, 2006). 
Construcción de paz es fortalecer escenarios para evitar recaídas violentas. Abarca atributos como DDR (procesos de desarme, desmovilización y reintegración de excombatientes), reconciliación, atención a población vulnerable, construcción de memoria y verdad, justicia transicional y reparación, prevención de la violencia y el crimen, reforma de las Fuerzas Armadas y de Policía, la reconstrucción y el desarrollo económico, la estabilización política y la participación del sector privado, la sociedad civil y la comunidad internacional en todos ellos (Galtung, 1975; Boutros-Ghali, 1992; Chetail, 2009; Rettberg, 2003, 2012). Entonces, hablar teóricamente de una guerra justa, en términos generales, gira en torno a dos puntos cruciales: la justicia de una guerra y la justicia de la forma en que se libra la guerra. Estos dos puntos — jus ad bellum y jus in bello, respectivamente- definen el debate sobre si una guerra es moral; aspectos jurídico-políticos que terminaron adhiriéndose a marcos posteriores de conflicto armado, con nuevas etiquetas, pero bajo los mismos fundamentos éticos.

Ni en escenarios clásicos ni contemporáneos de enfrentamientos armados se ha realizado un trabajo teórico importante para comprender y sistematizar los conceptos que encierran los contextos posteriores a enfrentamientos armados. Las consecuencias de la guerra son cruciales para la justicia de la guerra misma. Los líderes políticos a menudo invocan desarrollos de posguerra, como traer democracia o estabilidad como parte de justificar o condenar una guerra, pero no han llegado a un acuerdo acerca de cuáles de estos argumentos son moralmente convincentes (Bass, 2004). Pues, como lo sostiene DiMeglio (2005), la responsabilidad jurídica recae en individuos moralmente culpables. No obstante, dichos vínculos éticos pueden afectar la imparcialidad e inclusión durante los procesos de paz particulares. Por su parte, la nueva escuela contemporánea de DIP dotó de personalidad jurídica internacional a nuevos sujetos de derecho, como las organizaciones internacionales, permitiendo tan solo excepcionalmente el uso de la violencia legítima para resolver las controversias. Sin embargo, la violencia armada cambió de ropaje, proliferando confrontaciones entre sujetos y actores armados asimétricos: "Después de 1989, la proporción de conflictos armados que finalizaron en una mesa de negociación se duplicó — de 9\% entre 1946 y 1989, a 18\% entre 1990 y 2005-, mientras que la de victorias militares 
de alguna de las partes se redujo de forma drástica — de 54 a $14 \%$ en el mismo período_-" (Kreutz, 2010, citado en Ugarriza, 2013, p. 144).

Dentro de los nuevos sujetos, las organizaciones internacionales y las organizaciones de la sociedad civil son de vital importancia para el análisis del DH propuesto. Analicemos el impacto de la Corte Penal Internacional (CPI), y ofrezcamos cifras relativas a 2015, para comprender la importancia del proyecto piloto acordado en La Habana, entre el gobierno y las FARC, ejecutado con participación de organizaciones civiles de derechos humanos (OCDH) noruegas, italianas y danesas, principalmente, antes de firmado el Acuerdo.

\section{Metodología}

Se efectúa una aproximación teórica contemporánea de carácter jurídico-político, construida a través de elementos jurisprudenciales, doctrinales, resultados de web mining y de información recogida a través de entrevistas realizadas a informantes clave dentro del proceso de DH ejecutado en el marco del plan piloto, concentrándonos en lo ocurrido en el año 2015, creando una primera base que potenciará en el futuro mediano nuevas investigaciones de método comparado, al menos en el tiempo, del caso concreto de descontaminación del territorio colombiano. Para entender el DH de 2015 y dentro del Marco Jurídico para la Paz, se entrevistó, entre otros, a altos funcionarios de la Organización de los Estados Americanos (OEA) — coronel (r.) Guillermo Leal Abadía, jefe de misión del PAICMA en Colombiay del gobierno — brigadier general Rafael Alfredo Colón Torres, líder de la DAICMA, del Ministerio del Posconflicto, Derechos Humanos y Seguridad, y el coronel Germán Nicolás Pataquiva García, coordinador nacional-. 


\section{Contextualización. La problemática de las minas antipersona}

El artículo $2^{\circ}$ de la Convención de Ottawa define a las minas antipersona (MAP) como "artefacto explosivo concebido para que explosione por la presencia, la proximidad o el contacto de una persona, y que en caso de explosionar tenga la potencialidad de incapacitar, herir [o] matar a una o más personas" (Vicepresidencia de la República de Colombia, 2012). ${ }^{1}$

El origen de las MAP es la guerra civil de Estados Unidos, durante la década de 1800. La utilización a gran escala ocurrió durante la Segunda Guerra Mundial. No obstante, comenzaron a emplearse en diversos conflictos, tanto internos como externos, aumentando su producción:

Más de cincuenta países han producido [MAP]... Treinta y nueve ya han detenido la producción, y el comercio mundial se ha detenido casi por completo. Ninguno de los Estados parte en el Tratado de Prohibición de Minas las produce actualmente. Estados no parte se siguen reservando el derecho: China; Cuba; India; Irán; Birmania; Corea del Norte; Corea del Sur; Pakistán; Rusia; Singapur, y Vietnam. La producción real puede ser permanente en la India, Birmania, Pakistán y Corea del Sur... Algunos grupos armados no estatales o grupos rebeldes producen [MAP], en su mayoría de la variedad improvisada ${ }^{2}$ (International Campaign to Ban Landmines, s. f. b).

\footnotetext{
1 Definidas - artículo $2^{\circ}$ : “Convención sobre la prohibición del empleo, almacenamiento, producción y transferencia de minas antipersonales y sobre su destrucción”. 2 Traducción propia. Redacción original: "Over 50 countries have produced antipersonnel mines at some time, both for their own stocks and to supply others.

Thirty-nine of these states have now stopped production, and global trade has almost halted completely. None of the States Parties to the Mine Ban Treaty produces landmines anymore. Unfortunately, 11 States not party continue to reserve the right to do so: China, Cuba, India,
} 
Como estrategia de 'guerra', las MAP suponen bajos costos e importantes resultados: "Diseñada para mutilar en lugar de matar a un soldado enemigo [...] Exige más recursos cuidar de un soldado herido en el campo de batalla que encargarse de un soldado que ha sido asesinado" (International Campaign to Ban Landmines, s. f. b). ${ }^{3}$

Las MAP disminuyen las posibilidades de enfrentamiento armado, lo que se refleja en una menor cantidad de bajas; conducen a un terror generalizado, impidiendo invasiones o acercamientos; con sistemas de autodestrucción que no requieren un dispositivo de detonación que exponga a quien emplea el arma; de uso masivo y de bajo costo, perduran en el tiempo, lo que permite 'protección' a largo plazo, siendo de difícil y casi imposible detección, son 'el 'soldado perfecto', pues nunca duerme y nunca falla, no dejan de actuar frente a un cese de actividades bélicas y aunque han sido creadas para fines de guerra, no distinguen entre combatientes, adultos ni niños, pues se observa que sólo el diez por ciento de sus víctimas son combatientes" (Corte Constitucional de Colombia, 2000).

No obstante, los beneficios esbozados corresponden a un escenario inhumano que hizo insostenible cualquier argumento, incluso los de índole militar; entre otras consideraciones, ${ }^{4}$ se exponen las siguientes:

i) Uso indiscriminado que no selecciona a la víctima, lo que lleva a la mutilación y el homicidio de personas ajenas al conflicto.

Iran, Myanmar, North Korea, South Korea, Pakistan, Russia, Singapore and Vietnam. Actual production may be ongoing in only four of them: India, Myanmar, Pakistan, and South Korea. At the same time some non-state armed groups or rebel groups in various countries produce antipersonnel mines, mostly of the improvised variety".

3 Traducción propia. Redacción original: "A key characteristic of the weapon is that it is designed to maim rather than kill an enemy soldier. This follows the 'logic' that more resources are taken up caring for an injured soldier on the battlefield than dealing with a soldier who has been killed".

4 Argumentos expuestos por medios de comunicación, organizaciones gubernamentales y no gubernamentales y Estados, entre otros actores de la sociedad que coinciden en cuanto al carácter atroz de las MAP. 
ii) Busca sufrimiento —incluso como estrategia de guerra [...] el personal herido genera mayores costos que el personal fallecido(International Campaign to Ban Landmines, s. f. a)..$^{5}$

iii) Carecen de control absoluto. En la actualidad carece de mapeo. Afecta incluso al personal de socorro o desminado.

iv) Uso indefinido en el tiempo. Utilizadas incluso tras la finalización de la guerra o del conflicto: "Los civiles representan del 70\% al $85 \%$ de las bajas. Esto no es solo durante el conflicto; la mayoría de los países donde se reportaron víctimas están en paz" (International Campaign to Ban Landmines, s. f. a). ${ }^{6}$

v) Violación flagrante de los aspectos básicos del DIH.

vi) Supone pérdidas económicas cuantiosas, representadas, entre otros daños, en el medioambiental.

vii) Impide labores de socorro y asistencia apropiadas. Se requieren labores de rescate y cuidado más especializadas.

viii) Existen múltiples alternativas al empleo de las MAP que cumplen la misma finalidad sin el costo en vidas humanas ni las demás consecuencias descritas.

A finales del siglo $\mathrm{xx}$, las normativas internacional y nacional se preocuparon por la evidente desproporcionalidad de los medios de guerra - concretamente las MAP-, lo que hizo necesario prohibir el uso de armas de combate que excedan los fines bélicos en contravía absoluta de la dignidad humana y con una amenaza latente. Veamos los principales instrumentos exógenos:

\footnotetext{
5 Traducción propia. Redacción original: “They blow off their victims' legs, feet, toes and hands. They fire shrapnel into their faces and bodies. They kill".

6 Traducción propia. Redacción original: "Year after year, Landmine Monitor has reported that civilians account for 70 to 85 percent of casualties. This is not just during a conflict most of the countries where casualties are reported are at peace".
} 
Tabla 1. Principales instrumentos jurídicos internacionales

\begin{tabular}{|c|c|}
\hline Normativa & Contenido básico \\
\hline $\begin{array}{l}\text { Convención sobre probibiciones o restricciones } \\
\text { del empleo de ciertas armas convencionales que } \\
\text { puedan considerarse excesivamente nocivas o } \\
\text { de efectos indiscriminados y protocolos anexos, } \\
\text { especialmente el Protocolo sobre probibiciones } \\
\text { o restricciones del empleo de minas, armas trampa } \\
\text { y otros artefactos } \\
\text { Ginebra, } 1980\end{array}$ & $\begin{array}{l}\text { Regula el "empleo en tierra de las minas, } \\
\text { armas trampa y otros artefactos definidos } \\
\text { en [el Protocolo], incluidas las minas } \\
\text { sembradas para impedir el acceso a playas, } \\
\text { el cruce de vías acuáticas o el cruce de } \\
\text { ríos, pero no se aplica al empleo de minas } \\
\text { antibuques en el mar o en vías acuáticas } \\
\text { interiores" (Comité Internacional de la } \\
\text { Cruz Roja [CICR], 1980, art. } 1^{\circ} \text { ), lo que } \\
\text { generó restricciones en su empleo. Se } \\
\text { extraña una prohibición absoluta.7 }\end{array}$ \\
\hline $\begin{array}{l}\text { Protocolo sobre prohibiciones o } \\
\text { restricciones del empleo de minas, armas } \\
\text { trampa y otros artefactos (enmendado en } \\
1996 \text { ) }\end{array}$ & $\begin{array}{l}\text { Refuerzo de restricciones al empleo de las } \\
\text { MAP, sin que se consagre una prohibición } \\
\text { total. }\end{array}$ \\
\hline $\begin{array}{l}\text { Resolución } 51 / 45 \text { S del } 10 \text { de diciembre } \\
\text { de 1996, AGNU }\end{array}$ & $\begin{array}{l}\text { Exhortó a todos los Estados a procurar } \\
\text { decididamente concertar un acuerdo } \\
\text { internacional eficaz y de cumplimiento } \\
\text { obligatorio para prohibir el uso, el } \\
\text { almacenamiento, la producción y } \\
\text { la transferencia de las MAP. Si bien } \\
\text { este documento no es jurídicamente } \\
\text { vinculante, sí marcó en el contexto } \\
\text { internacional una decisión política } \\
\text { concertada que resulta trascendental en el } \\
\text { manejo de esta problemática. }\end{array}$ \\
\hline
\end{tabular}

(Continúa)

7 Acogidos en Colombia mediante la Ley 469 de 1998 (5 de agosto), que aprueba la Convención sobre prohibiciones o restricciones del empleo de ciertas armas convencionales que puedan considerarse excesivamente nocivas o de efectos indiscriminados (Ginebra, 10 de octubre de 1980), y sus cuatro protocolos: el "Protocolo I. Sobre fragmentos no localizables", adoptado el 10 de octubre de 1980 con la Convención; el "Protocolo II. Sobre prohibiciones o restricciones del empleo de minas, armas trampa y otros artefactos", enmendado el 3 de mayo de 1996 en Ginebra; el "Protocolo III. Sobre prohibiciones o restricciones del empleo de armas incendiarias", adoptado el 10 de octubre con la Convención; y el "Protocolo adicional, considerado como IV, sobre armas láser cegadoras", aprobado en Viena el 13 de octubre de 1995. 


\begin{tabular}{|l|l|}
\hline \multicolumn{1}{|c|}{ Normativa } & \multicolumn{1}{c|}{ Contenido básico } \\
\hline $\begin{array}{l}\text { Proceso de Ottawa, }{ }^{8} \text { que condujo a la } \\
\text { adopción del Tratado de Prohibición de } \\
\text { Minas (septiembre de 1997) }\end{array}$ & $\begin{array}{l}\text { Supuso un cambio en la regulación en } \\
\text { materia de MAP, pues consagró como } \\
\text { obligación general la prohibición absoluta } \\
\text {-entre otros aspectos - del empleo, } \\
\text { desarrollo, producción y almacenamiento de } \\
\left.\text { las minas antipersona (art. } 1^{\circ}\right) \text {. Así mismo, se } \\
\text { establece el deber de destruirlas (art. 1.2). }{ }^{10}\end{array}$ \\
\hline
\end{tabular}

Fuente: elaboración de las autoras.

8 Impulsado desde la Campaña Internacional para la Prohibición de las Minas Antipersona, en colaboración con algunos Estados a los que se les conoció como el Core Group (conformado por Austria, Bélgica, Canadá, Irlanda, Filipinas, México, los Países Bajos, Noruega, Sudáfrica, Suiza, Colombia, Alemania, Brasil, Francia, Malasia, Nueva Zelanda, Portugal, Eslovenia, el Reino Unido y Zimbabue), el Comité Internacional de la Cruz Roja y la onu. La Conferencia de Ottawa (1996), en la que se sentaron las bases del posterior convenio: "Al término de la Conferencia, el ministro de Relaciones Exteriores del país organizador, Lloyd Axworthy, concluyó su discurso con un llamamiento a todos los gobiernos para que regresaran a Ottawa, antes de finalizar 1997, con objeto de firmar dicho tratado. Esta audaz iniciativa, a pesar de haber sido inmediatamente apoyada por el presidente del CICR, Cornelio Sommaruga, que asistió a la Conferencia, el secretario general de las Naciones Unidas y la Campaña Internacional de Erradicación de las Minas Terrestres (icbl), causó gran sorpresa entre los gobiernos participantes, y en ningún caso cabía garantizar su éxito. De hecho, hasta entonces s[o]lo [cincuenta] Estados se habían declarado públicamente partidarios de una completa prohibición a nivel mundial de las minas antipersona [...], y muchos consideraban que el Protocolo II enmendado era por entonces un acuerdo internacional suficientemente riguroso" (Maslen \& Herby, 1998).

9 Adoptado en la Conferencia Diplomática sobre la Prohibición Total Internacional de Minas Terrestres Antipersonal (Oslo, 1-18 de septiembre de 1997) (Organización de las Naciones Unidas, 1997).

“El 3/5/1996, en Ginebra la primera Conferencia de Examen de la Convención de 1980 sobre ciertas Armas Convencionales [1] (cac), el sentimiento de decepción era general, debido a que los Estados [parte] no consiguieron alcanzar un consenso por lo que respecta a la adopción de eficaces medidas para combatir la plaga mundial de las minas terrestres. Las modificaciones introducidas en el Protocolo II de LA CAC, el 3 de mayo de 1996 [2] (Protocolo II enmendado), fueron acogidas con gran satisfacción, pero no bastaban para prohibir totalmente estas armas; esta iniciativa fue respaldada entonces por más de [cuarenta] Estados. Deseosa de potenciar este impulso internacional, cuyo ritmo se habría enlentecido sin su apoyo, la delegación canadiense anunció que Canadá organizaría, a finales del año, una reunión de todos los Estados partidarios de la prohibición, con objeto de trazar una estrategia para orientar a la comunidad internacional hacia la proscripción mundial de las minas antipersona” (Maslen \& Herby, 1998).

"Ante el fracaso de las negociaciones, y dada la palmaria necesidad de acrecentar los esfuerzos para lograr dicho instrumento, fue posible, bajo la iniciativa de Canadá, la adopción de la Convención de Ottawa, en septiembre de 1997”' (ElTiempo, 2009). Ver Maslen y Herby (1998).

10 Se permitió retención para "el desarrollo de técnicas de detección, limpieza o destrucción de minas y el adiestramiento en dichas técnicas", y su transferencia, únicamente con 
Mientras numerosos desafíos permanecen, el uso de minas terrestres, así como su producción y comercio mundial, se han reducido drásticamente gracias al Tratado de Prohibición de Minas. Decenas de millones de MAP han sido destruidas, grandes extensiones de tierra se han limpiado y devuelto a las comunidades para el uso seguro, y los derechos y necesidades de las víctimas de las minas terrestres están recibiendo una mayor atención. Colombia se ha sumado a los Estados que han consagrado normas concretas que propugnan la aplicación de las disposiciones básicas reconocidas en el contexto internacional:

Tabla 2. Normatividad interna

\begin{tabular}{|l|l|}
\hline \multicolumn{1}{|c|}{ Normativa } & \multicolumn{1}{c|}{ Contenido básico } \\
\hline Constitución Política - 1991 & $\begin{array}{l}\text { Asigna al Estado el monopolio de las } \\
\text { armas y determina las limitaciones que } \\
\text { regulan la posesión por los particulares } \\
\text { (art. 223). } \\
\text { Sumada la necesidad de emprender, en }\end{array}$ \\
& $\begin{array}{l}\text { conflicto, acciones humanitarias para: } \\
\text { i) mantener la paz, ii) impedir la guerra } \\
\text { interior y iii) preservar el orden público, } \\
\text { la tranquilidad y seguridad, asumiendo } \\
\text { compromisos concretos orientados a la } \\
\text { humanización de la guerra. }\end{array}$ \\
\hline $\begin{array}{l}\text { Ley 554 de 2000 (14 de enero), "se } \\
\text { aprueba la Convención sobre la probibición } \\
\text { del empleo, almacenamiento, produccióny } \\
\text { transferencia de minas antipersonales y sobre su } \\
\text { destrucción, Oslo 18/09/1997" }\end{array}$ & $\begin{array}{l}\text { Adopción integral de disposiciones. Se } \\
\text { destaca la prohibición integral del empleo } \\
\text { de MAP en Colombia y su disposición de } \\
\text { descontaminación. }\end{array}$ \\
\hline
\end{tabular}

(Continúa)

fines de su propia destrucción (art. $3^{\circ}$ ). En dicho tratado, además, se reguló el compromiso de destruir las existencias de MAP (art. $4^{\circ}$ ); el deber de destruir las MAP presentes en zonas minadas $\left(\right.$ art. $\left.5^{\circ}\right)$; lo concerniente a la cooperación y asistencia internacionales para solicitar y recibir asistencia de otros Estados en materia de map (labores de limpieza de minas, principalmente) (art. $6^{\circ}$ ); se adoptaron medidas de transparencia a efectos de controlar y verificar el cumplimiento del documento internacional $\left(\operatorname{art.} 7^{\circ}\right)$; y el deber de crear condiciones legislativas que propugnen la imposición de sanciones por omitir el cumplimiento de este tratado $\left(\right.$ art. $\left.9^{\circ}\right)$, entre otros aspectos. 


\begin{tabular}{|c|c|}
\hline Normativa & Contenido básico \\
\hline $\begin{array}{l}\text { Ley } 759 \text { de } 2002 \text { ( } 25 \text { de julio), "normas } \\
\text { para dar cumplimiento a la Convención } \\
\text { sobre la probibición del empleo, almacenamiento, } \\
\text { producción y transferencia de minas } \\
\text { antipersonales y sobre su destrucción, y se fijan } \\
\text { disposiciones con el fin de erradicar en } \\
\text { Colombia el uso de las minas antipersona" }\end{array}$ & $\begin{array}{l}\text { Creó tipos penales específicos en relación } \\
\text { con las MAP, así como para su destrucción. } \\
\text { Creó la Comisión Intersectorial Nacional } \\
\text { para la Acción contra Minas Antipersonal. } \\
\text { Se regulan las prácticas o misiones } \\
\text { humanitarias. } \\
\text { Creó el Observatorio de Minas } \\
\text { Antipersonal. } \\
\text { Reglamentó la incautación, la cooperación } \\
\text { y la asistencia internacional. }{ }^{11}\end{array}$ \\
\hline $\begin{array}{l}\text { Decreto } 2535 \text { de } 1993 \text { ( } 17 \text { de diciembre), } \\
\text { "normas sobre armas, municiones y } \\
\text { explosivos" }\end{array}$ & $\begin{array}{l}\text { Desarrolla el artículo } 223 \text { de la } \\
\text { Constitución: requisitos para la tenencia } \\
\text { y porte de armas (y asuntos similares). } \\
\text { El artículo } 49 \text { del decreto prohíbe } \\
\text { expresamente "la venta y uso particular de } \\
\text { municiones explosivas, tóxicas, expansivas } \\
\text { y de fragmentación". }\end{array}$ \\
\hline $\begin{array}{l}\text { Documento Conpes (Consejo Nacional } \\
\text { de Política Económica y Social) } 2567 \text { de } \\
2009\end{array}$ & $\begin{array}{l}\text { Integró el marco de la política para } \\
\text { la ejecución de la Acción Integral } \\
\text { contra Minas Antipersonal (AICMA) } \\
\text { en el período 2009-2019, de acuerdo } \\
\text { con los compromisos adquiridos en } \\
\text { la Convención de Ottawa. Planteó la } \\
\text { problemática de las MAP y describió las } \\
\text { líneas estratégicas de corto, mediano y } \\
\text { largo plazo. }\end{array}$ \\
\hline $\begin{array}{l}\text { Decreto } 2150 \text { de } 2007 \text { ( } 12 \text { de junio), } \\
\text { "crea programa presidencial en el } \\
\text { Departamento Administrativo de la } \\
\text { Presidencia de la República" }\end{array}$ & $\begin{array}{l}\text { Creó el Programa Presidencial para la } \\
\text { AICMA (Presidencia de la República). }\end{array}$ \\
\hline $\begin{array}{l}\text { Ley } 1421 \text { de } 2010 \text {, "prorroga la Ley } 418 \\
\text { de } 1997 \text {, prorrogada y modificada por las } \\
\text { leyes } 548 / 1999,782 / 2002 \text { y } 1106 / 2006 "\end{array}$ & $\begin{array}{l}\text { Relación específica con actividades de DH } \\
\text { y su realización por organizaciones civiles. }\end{array}$ \\
\hline
\end{tabular}

(Continua)

11 Anteriormente se expidió la Ley 469 de 1998. 


\begin{tabular}{|c|c|}
\hline Normativa & Contenido básico \\
\hline $\begin{array}{l}\text { Decreto } 3750 \text { de } 2011 \text { (10 de octubre), } \\
\text { "reglamenta el artículo } 9^{\circ} \text { Ley } 1421 / 2010, \\
\text { "prorroga Ley } 418 / 1997, \text { prorrogada } \\
\text { y modificada por las leyes 548/1999, } \\
782 / 2002 \text { y 1106/2006" }\end{array}$ & $\begin{array}{l}\text { Establece que el gobierno efectuará } \\
\text { actividades de DH en el territorio nacional } \\
\text { por intermedio del Ministerio de Defensa } \\
\text { Nacional (y, subsidiariamente, con } \\
\text { organizaciones civiles) y que se realizarán } \\
\text { progresivamente conforme los estándares } \\
\text { internacionales aplicables. Además, } \\
\text { creó una instancia interinstitucional } \\
\text { de DH y determinó sus funciones. Fijó } \\
\text { los estándares de DH adoptados por } \\
\text { resolución del Ministerio de Defensa } \\
\text { Nacional, entre otros. }\end{array}$ \\
\hline Estándares de DH & $\begin{array}{l}\text { Elaborados para acreditar OCDH. } \\
\text { Consagró derechos y obligaciones de DH. }\end{array}$ \\
\hline $\begin{array}{l}\text { Informes preventivos de la Procuraduría } \\
\text { General de la Nación }\end{array}$ & $\begin{array}{l}\text { Informes de discusión de diversos temas } \\
\text { sobre MAP, desminado y derechos y } \\
\text { deberes derivados de aquellos. }\end{array}$ \\
\hline
\end{tabular}

Fuente: elaboración de las autoras.

En la línea de protección de víctimas, existe también una gran variedad de disposiciones (sobre las que no se hacen mayores comentarios), entre otras:

i) Ley 361 de 1997 (7 de febrero), "por la cual se establecen mecanismos de integración social de las personas en situación de discapacidad y se dictan otras disposiciones".

ii) Decreto 3990 de 2007 (17 de octubre), "por el cual se reglamenta la subcuenta del seguro de riesgos catastróficos y accidentes del tránsito del Fondo de Solidaridad y Garantía, Fosyga, se establecen las condiciones de operación del aseguramiento de los riesgos derivados de daños corporales causados a las personas en accidentes de tránsito, eventos catastróficos y terroristas, las condiciones generales del seguro de daños corporales causados a las personas en accidentes de tránsito, SOAT, y se dictan otras disposiciones".

iii) Decreto 2973 de 2010 (6 de agosto), "por el cual se fijan los criterios para la prestación de los servicios de rehabilitación física y mental a las víctimas de la violencia política y se dictan otras disposiciones”. 
Por lo demás, han surgido varias organizaciones y asociaciones dedicadas al tratamiento de las víctimas de MAP. Se destacan, por la labor, las siguientes:

i) Programa Presidencial para la Acción Integral contra Minas Antipersonal (PAICMA), dependencia del Departamento Administrativo de la Presidencia de la República.

ii) Unidad para la Atención y Reparación Integral a las Víctimas.

iii) Ministerio de Salud y Protección Social, mediante el Programa de Atención Psicosocial y Salud Integral a Víctimas (PAPSIVI).

iv) Campaña Colombiana contra Minas.

v) ONG Handicap International.

vi) CICR.

vii) Centro Integral de Rehabilitación de Colombia (CIREC).

viii) Secretariado Nacional de Pastoral Social/Cáritas Colombiana.

ix) Fundación Tierra de Paz.

\section{Tratamiento penal del minado en el contexto de la Corte Penal Internacional}

Las advertencias que hicieron a Colombia Kofi Annan, ex secretario general de la ONU, y Fatou Bensouda, ${ }^{12}$ fiscal de la Corte Penal Internacional (CPI), quienes apuntaron a que aun en el marco del proceso de paz se deben respetar estándares internacionales mínimos, repercuten en las decisiones sobre el minado/desminado colombiano, so pena de que el tribunal internacional de responsabilidad individual aplique las sanciones contenidas en el Estatuto de Roma (ER), cuya vigencia inició el $1^{\circ}$ de septiembre de 2002.

La CPI, con sede en La Haya, organización internacional de carácter permanente, con vocación universal, aboga — tras la experiencia de los tribunales internacionales creados para salvaguardar situaciones

\footnotetext{
12 Según Bensouda, "cualquier acuerdo de paz al que se llegue, así como el marco jurídico para la paz, debe ser compatible con el Estatuto de Roma” (El Tiempo, 2014).
} 
concretas en el pasado (Tokio, Núremberg, la antigua Yugoslavia y Ruanda, entre los principales)—, desde el contexto internacional, por la responsabilidad de quien comete delitos con trascendencia internacional.

Su jurisdicción es complementaria a la estatal, cuando esta no actúe conforme a la ley o no pueda hacerlo, respetando la irretroactividad del Estatuto (salvo que el Estado pacte lo contrario), y que configure punibles de i) genocidio, ii) crímenes de lesa humanidad, iii) crímenes de guerra y iv) crimen de agresión (Corte Penal Internacional, 1998); delitos no prescriptibles (Corte Constitucional de Colombia, 2012) y que pueden ser sancionados con hasta 30 años de prisión y, excepcionalmente, con cadena perpetua.

Colombia adoptó el ER y reconoció competencia a la CPI, razón por la que el DH y sus crímenes derivados deben respetar unos mínimos estándares internacionales. El minado se adecúa a los delitos de competencia de la CPI, tanto como i) crimen de lesa humanidad ${ }^{13}$ (ER, art. $\left.7^{\circ}\right)$, siempre que, de forma generalizada y sistemática, contra una población civil se cometa asesinato u otros actos inhumanos de carácter similar que causen intencionalmente grandes sufrimientos, o atenten gravemente contra la integridad física o la salud mental o física, condiciones que son connaturales a la utilización de las MAP; como ii) crimen de guerra ${ }^{14}$ (ER, art. $8^{\circ}$ ), sobre la comisión en gran

13 De acuerdo con la Corte Constitucional de Colombia (2013), estas son las "características de los delitos de lesa humanidad: i) causar sufrimientos graves a la víctima o atente contra su salud mental o física; ii) inscribirse en el marco de un ataque generalizado y sistemático; iii) estar dirigidos contra miembros de la población civil; y iv) ser cometidos por uno o varios motivos discriminatorios especialmente por razones de orden nacional, político, étnico, racial o religioso. [...] Al examinar la constitucionalidad de la ley aprobatoria del Estatuto de Roma —Sentencia C-578 de 2002_, la Corte consideró que los delitos de lesa humanidad son actos inhumanos cometidos como parte de un ataque generalizado o sistemático contra una población civil, ya sea en tiempo de guerra externo, conflicto armado interno o paz".

14 "Crímenes de guerra: ciertas violaciones graves del derecho de los conflictos armados que los Estados decidieron sancionar en el ámbito internacional" (Corte Constitucional, 2013). Así mismo, conforme con el Estatuto de Roma, "los crímenes de guerra incluyen un amplio listado de conductas específicamente aplicables a conflictos armados no internacionales [...]" (Corte Constitucional, 2013). 
escala, lo que genera homicidio intencional y causa deliberadamente grandes sufrimientos, o atenta gravemente contra la integridad física, lo que a su vez vulnera las normas sobre conflictos armados nacionales. Conforme a ello, en las mesas de negociación alguna respuesta desde la perspectiva penal deberá ofrecerse en cuanto al minado, pues este es considerado un crimen de trascendencia internacional en el que podría entrar e intervenir la CPI. ${ }^{15}$

\section{Tratamiento penal del minado en Colombia}

El minado presenta particularidades derivadas del conflicto armado interno que conducen a un tratamiento disímil en razón de la víctima del punible. A continuación, se expone, según escenarios concretos, cómo se configuraría la responsabilidad penal derivada del empleo de MAP:

Tabla 3. Tipologías delictuales por el empleo de las MAP

\begin{tabular}{|l|l|l|}
\hline \multicolumn{1}{|c|}{ Contexto } & \multicolumn{1}{|c|}{ Escenario } & $\begin{array}{l}\text { Delito y pena de prisión } \\
\text { atribuida en meses en el Código } \\
\text { Penal colombiano }\end{array}$ \\
\hline $\begin{array}{l}\text { De los delitos de } \\
\text { peligro común } \\
\text { o que pueden } \\
\text { ocasionar grave } \\
\text { perjuicio para la } \\
\text { comunidad y otras } \\
\text { infracciones. }\end{array}$ & $\begin{array}{l}\text { Simple minado con } \\
\text { independencia de que se } \\
\text { ocasione daño o situación } \\
\text { alguna a terceros (ausencia de } \\
\text { explosión). }^{17}\end{array}$ & $\begin{array}{l}\text { Empleo, producción, } \\
\text { comercialización, cesión y } \\
\text { almacenamiento de MAP (art. } \\
\text { 367-A). } \\
\text { Penas de } 160 \text { a } 270 .^{18}\end{array}$ \\
\hline
\end{tabular}

(Continua)

\footnotetext{
15 En las mesas de negociación del proceso de paz, se estableció el desarrollo de investigaciones correspondientes por crímenes de lesa humanidad y por crímenes de guerra.

16 Se aclara que para la mayoría de las conductas se contempla además la pena de multa y de inhabilitación para el ejercicio de derechos y funciones públicas.

17 Genera excepción en los términos allí previstos para el Ministerio de Defensa Nacional.

18 Existe un delito denominado "utilización de medios y métodos de guerra ilícitos" (Código Penal, art. 142); no obstante, no se aplicaría, pues existe un delito especial para dichos fines, que sería el contenido en el artículo 367-A del Código.
} 


\begin{tabular}{|c|c|c|c|}
\hline Contexto & Escenario & \multicolumn{2}{|c|}{$\begin{array}{c}\text { Delito y pena de prisión } \\
\text { atribuida en meses en el Código } \\
\text { Penal colombiano }\end{array}$} \\
\hline & $\begin{array}{l}\text { Si se trata de MAP con } \\
\text { dispositivo antimanipulación } \\
\text { o armado como trampa } \\
\text { explosiva. }\end{array}$ & \multicolumn{2}{|c|}{$\begin{array}{l}\text { Es el mismo delito, pero se } \\
\text { agrava la pena, que queda de } \\
240 \text { a } 360 .\end{array}$} \\
\hline & $\begin{array}{l}\text { Promoción, ayuda, facilitación, } \\
\text { estímulo o inducción a } \\
\text { participar en las actividades } \\
\text { aludidas (simple minado). }\end{array}$ & \multicolumn{2}{|c|}{$\begin{array}{l}\text { Responderá penalmente por el } \\
\text { delito contenido en el artículo } \\
\text { 367-B, con penas de } 96 \text { a } 180 .\end{array}$} \\
\hline \multirow{4}{*}{$\begin{array}{l}\text { Delitos contra las } \\
\text { personas y bienes } \\
\text { protegidos por el } \\
\text { DIH. }\end{array}$} & $\begin{array}{l}\text { Persona protegida }{ }^{19} \text { que fallece } \\
\text { por contacto con MAP. }\end{array}$ & \multicolumn{2}{|c|}{$\begin{array}{l}\text { Homicidio en persona } \\
\text { protegida (art. 135), con penas } \\
\text { de } 480 \text { a } 600 .\end{array}$} \\
\hline & \multirow{3}{*}{$\begin{array}{l}\text { Persona protegida lesionada } \\
\text { por contacto con MAP. }\end{array}$} & \multicolumn{2}{|c|}{$\begin{array}{l}\text { Lesiones personales en } \\
\text { persona protegida (art. } \\
\text { 136), con las mismas penas } \\
\text { aplicables al delito de lesiones } \\
\text { personales incrementadas hasta } \\
\text { en una tercera parte. }\end{array}$} \\
\hline & & $\begin{array}{l}\text { Pérdida } \\
\text { anatómica o } \\
\text { funcional de } \\
\text { un órgano o } \\
\text { miembro. }\end{array}$ & $\begin{array}{l}\text { La pena será } \\
\text { de } 96 \text { a } 240 .\end{array}$ \\
\hline & & $\begin{array}{l}\text { Pérdida } \\
\text { anatómica de } \\
\text { un órgano o } \\
\text { miembro. }\end{array}$ & $\begin{array}{l}\text { La pena será } \\
\text { de } 96 \text { a } 320 .\end{array}$ \\
\hline
\end{tabular}

(Continúa)

19 Son personas protegidas, según el parágrafo del artículo 135 del Código Penal: población civil; personas que no participan en hostilidades y los civiles en poder del adversario; heridos, enfermos o náufragos fuera de combate; personal sanitario o religioso; periodistas o corresponsales acreditados; combatientes que hayan depuesto las armas por captura, rendición u otra causa; quienes antes del comienzo de las hostilidades fueren considerados como apátridas o refugiados, y cualquier otra persona que tenga aquella condición en virtud de los convenios I, II, III y IV de Ginebra de 1949, los protocolos adicionales I y II de 1977, y otros que llegaren a ratificarse. 
18 / Diana Patricia Arias - Juanita María Ospina Perdomo

\begin{tabular}{|c|c|c|c|}
\hline Contexto & Escenario & $\begin{array}{r}\text { Delito y } p \\
\text { atribuida en } n \\
\text { Penal }\end{array}$ & $\begin{array}{l}\text { a de prisión } \\
\text { es en el Código } \\
\text { ombiano }\end{array}$ \\
\hline & $\begin{array}{l}\text { Bienes protegidos por el } \mathrm{DIH}^{20} \\
\text { que resultan destruidos por el } \\
\text { contacto con una mina. }\end{array}$ & \multicolumn{2}{|c|}{$\begin{array}{l}\text { Responderá penalmente por el } \\
\text { delito contenido en el artículo } \\
\text { 154. Penas de } 80 \text { a } 180 .\end{array}$} \\
\hline & $\begin{array}{l}\text { Medio ambiente que en } \\
\text { desarrollo del conflicto } \\
\text { armado resulta afectado por } \\
\text { una mina. }\end{array}$ & \multicolumn{2}{|c|}{$\begin{array}{l}\text { Delito de destrucción del } \\
\text { medio ambiente (art. 164), con } \\
\text { pena de } 160 \text { a } 270 .\end{array}$} \\
\hline \multirow{4}{*}{$\begin{array}{l}\text { Delitos contra la } \\
\text { vida e integridad } \\
\text { personal. }\end{array}$} & $\begin{array}{l}\text { Persona que forma parte } \\
\text { del conflicto (no es persona } \\
\text { protegida) y fallece ante el } \\
\text { contacto con una MAP. }\end{array}$ & \multicolumn{2}{|c|}{$\begin{array}{l}\text { Delito de homicidio (art. 103), } \\
\text { con pena de } 208 \text { a } 450 .^{21}\end{array}$} \\
\hline & \multirow{3}{*}{$\begin{array}{l}\text { Persona que forma parte } \\
\text { del conflicto (no es persona } \\
\text { protegida) y resulta lesionada } \\
\text { ante el contacto con una MAP. }\end{array}$} & \multicolumn{2}{|c|}{$\begin{array}{l}\text { Delito de lesiones personales } \\
\text { (arts. } 111 \text { y ss.). La pena } \\
\text { depende de la naturaleza de la } \\
\text { lesión. }^{22}\end{array}$} \\
\hline & & $\begin{array}{l}\text { Pérdida } \\
\text { anatómica o } \\
\text { funcional de } \\
\text { un órgano o } \\
\text { miembro. }^{23}\end{array}$ & $\begin{array}{l}\text { La pena será } \\
\text { de } 96 \text { a } 180 .\end{array}$ \\
\hline & & $\begin{array}{l}\text { Pérdida } \\
\text { anatómica de } \\
\text { un órgano o } \\
\text { miembro. }\end{array}$ & $\begin{array}{l}\text { La pena será } \\
\text { de } 96 \text { a } 240 .\end{array}$ \\
\hline
\end{tabular}

(Continua)

20 El DIH entiende por bienes, conforme con el parágrafo del artículo 154 del Código Penal, a saber: los de carácter civil que no sean objetivos militares; los culturales y los lugares destinados al culto; los indispensables para la supervivencia de la población civil; los elementos que integran el medio ambiente natural; y las obras e instalaciones que contienen fuerzas peligrosas.

21 Se podría agravar si se efectúa con fines terroristas (400-600).

22 Se podría agravar de un tercio a la mitad si se efectúa con fines terroristas.

23 Se plantea este ejemplo por ser la lesión más común cuando esta es ocasionada por la explosión de una MAP. 


\begin{tabular}{|c|c|c|}
\hline Contexto & Escenario & $\begin{array}{c}\text { Delito y pena de prisión } \\
\text { atribuida en meses en el Código } \\
\text { Penal colombiano }\end{array}$ \\
\hline $\begin{array}{l}\text { Delitos contra } \\
\text { el patrimonio } \\
\text { económico. }\end{array}$ & $\begin{array}{l}\text { Daño a cosas (no protegidas) } \\
\text { con ocasión de la explosión de } \\
\text { la MAP. }\end{array}$ & $\begin{array}{l}\text { Delito de daño en bien ajeno } \\
\text { (art. 265), con pena de } 16 \text { a } 90 . \\
\text { Si la cuantía del daño es } \\
\text { inferior a diez salarios mínimos } \\
\text { legales mensuales vigentes } \\
\text { (smlmv), la pena será de } 16 \\
\text { a } 36 . \\
\text { Si es superior a } 100 \text { smlmv, la } \\
\text { pena será de } 21,3 \text { a } 135 . \\
\text { Si es un bien del Estado, la } \\
\text { pena será de } 21,3 \text { a } 135 .\end{array}$ \\
\hline
\end{tabular}

Fuente: elaboración de las autoras.

Un tratamiento completamente disímil, objeto de múltiples cuestionamientos, por cuanto no pareciese responder a la gravedad de lo acaecido, sobre la base de un trato diferenciado para aquellos punibles que se desarrollan en contra de personas protegidas (delitos contra personas y bienes protegidos por el DIH) y aquellos que atentan contra la vida e integridad personal (homicidio y lesiones personales), así como los que se orientan a la garantía del patrimonio privado (daño en bien ajeno); no así en razón del medio del enfrentamiento empleado.

\section{Implicaciones y consecuencias del desminado}

Toda vez que uno de los aspectos de decisión de las mesas de negociación apuntó al desminado, es relevante aludir aquí a lo que supone la actividad de desminado, dimensionando las implicaciones derivadas; la forma en que normalmente se tipificaría en Colombia el aviso en tiempo sobre la ubicación de una MAP (presencia o no de tentativa) y la responsabilidad que se puede derivar de sucesos fatales o, por lo menos, de resultados punibles en la actividad de desminado, entre otros. 


\section{Estado de la cuestión del posconflicto en Colombia}

Ante un conflicto armado, las soluciones jurídicas suelen oscilar entre el uso legítimo de la violencia y los modelos alternativos de justicia transicional, una inclinación hacia la solución alternativa para la resolución de conflictos (Molano-Rojas, 2015). La jurisprudencia del primer tribunal internacional para considerar las violaciones al DIH parece haber tenido la virtud de extender a todos los conflictos armados normas solo concebidas para los de carácter internacional. Un punto de partida resultó la extensión operada por la jurisprudencia del Tribunal Penal Internacional para la antigua Yugoslavia, la cual se fundamentó en los estándares tradicionales consagrados por los Convenios de Ginebra y sus protocolos adicionales de 1977, que intentaron completar el esquema de posguerra.

La existencia de un conflicto armado es la circunstancia objetiva que permite la aplicación concreta del DIH, dada la existencia de normas convencionales o consuetudinarias. El carácter peculiar del conjunto normativo caracterizado como derecho de Ginebra - su expreso y deliberado objetivo de proteger a las víctimas del conflicto- ha sido el disparador de una doctrina pacífica y bien consolidada respecto del carácter objetivo que supone la existencia del conflicto y de su independencia respecto de la doctrina del uso de fuerza instituida a la luz de las competencias con que la comunidad internacional ha dotado al Consejo de Seguridad de la ONU. Subyace un DIH concebido bajo criterios cualitativamente distintos a los imperantes en la normativa anterior a la Segunda Guerra Mundial, aunque dirigido a la protección de, aproximadamente, el mismo objetivo (Valladares, 2003).

Ahora, centrándonos en el uso de las MAP dentro de confrontaciones armadas, si bien la ONU informó sobre el uso en Afganistán, Pakistán, Yemen, Siria, Tailandia, Túnez y Colombia, nuestro país solamente adhirió al tratado contra las MAP en 2001. No obstante, la realidad práctica demuestra que el uso de estas armas representa un gran desafío para alcanzar la paz en Colombia. La nueva coyuntura del Marco Jurídico para la Paz en Colombia representa un paso adelante en la consecución efectiva de encaminar el Estado a un escenario de 
posconflicto. Concepto definido para el contexto colombiano como el período de tiempo que sigue a la superación total o parcial de los conflictos armados, con un único atributo: la reducción del número de homicidios relacionados con el conflicto por debajo de un umbral determinado (Universidad del Rosario, s. f.).

Existen dos miradas típicas sobre el posconflicto: en primer lugar, se lo entiende "como una situación de salida o superación de la guerra que propone el establecimiento de procesos de concertación y negociación en los que participen, directa o indirectamente, los distintos actores armados y sociales que hacen parte del conflicto" (Pérez, 2011, p. 135); $\mathrm{y}$, en segunda instancia, se lo ve como un período que sigue a la superación total o parcial de los conflictos armados, con un único atributo: la reducción de la cifra de homicidios relacionados con el conflicto por debajo de un umbral determinado, que le otorga o le niega el estatus de conflicto activo (Ugarriza, 2013). Sin embargo, una mirada práctica del posconflicto se debate entre un marco de impunidad para los actores armados ilegales por la imposición de penas alternativas, o una cesión jurídico-política necesaria para que dichos actores dejen las armas.

No obstante, y para fines académicos, es posible entenderlo como una transición de las nuevas guerras o guerras asimétricas a la superación de los estados bélicos, de lo que se rescatan dos elementos: la participación activa de los actores involucrados en el conflicto y la reducción de la cantidad de muertes derivadas de este.

El marco necesario para desarrollar un posconflicto requiere coordenadas específicas, entre las que encontramos el contexto, la acción en las víctimas, la rehabilitación de las víctimas, la cooperación internacional, el avance y, finalmente, la asistencia humanitaria (Garzón, Parra \& Pineda, 2003). Así mismo, es un proceso gradual que se ha clasificado en dos grandes momentos: el posconflicto parcial se presenta cuando cesan los combates entre los actores armados ilegales y los sujetos legales que detentan la violencia legítima del Estado; y el posconflicto total ocurre cuando se firma un acuerdo de paz entre ambos o porque una parte impulsó a la otra en dicha dirección (Garzón, et al., 2003). 
En ambos momentos es importante seleccionar adecuadamente las herramientas de la reconstrucción y la rehabilitación, con el fin de obtener una nueva infraestructura posbélica y un nuevo diseño para el marco humanitario, social, político e institucional, en pro de avanzar hacia nuevas formas de dirección del Estado en cuestión (Garzón, et al., 2003). Consolidando el concepto de construcción de la paz: un fortalecimiento y solidificación de la paz para evitar la recaída en el conflicto (Ugarriza, 2013), surgen dos posturas: la minimalista, que se entabla en términos de reconstrucción de infraestructura y eliminación de cualquier tipo de incentivo que genere un ambiente propicio para el conflicto; y la maximalista, en relación directa con la rehabilitación.

La construcción de la paz fomentará el desarrollo económico, político y social del Estado, lo que contribuirá a la superación de las causas estructurales de los conflictos, "como, por ejemplo, la pobreza, la inequidad y la exclusión que estas generan" (Rettberg, 2003), en un proyecto de largo plazo, mediante el fortalecimiento de las instituciones políticas, socioeconómicas y culturales viables y capaces de superar los orígenes del conflicto. En cuanto al marco judicial, la construcción de la paz debe escoger entre una amnistía y la persecución a fondo de los culpables de violaciones de derechos humanos, razón por la que esta es "una decisión entre brindar estabilidad inmediata al nuevo régimen protegiendo a una minoría (una postura minimalista) a costa de la justicia y la reconciliación social plenas (un objetivo maximalista)" (Rettberg, 2003). Sin embargo, frente al uso de las minas, al tipificarlo como un crimen de lesa humanidad debemos enfrentarnos a un proyecto de $\mathrm{DH}$, pero no es posible indultar este tipo de crímenes internacionales generando bisagras necesarias para cerrar las posturas minimalistas, puesto que no es posible amnistiar tales acciones atroces.

La voluntad de convivencia en un proceso que pasa del autoritarismo, así no sea declarado, a la democracia debe brindar espacios políticos transparentes y "marcos legales [...] que sustenten las libertades y los derechos" (Azpuru, Blanco, Córdova, Loya, Ramos \& Zapata, 2007); por eso, la importancia del sector social en la aceptación de los 
acuerdos de paz. El principio fundamental de negociación en bloque se basa en que nada está acordado hasta que todo esté acordado, y una vez acordado, se somete a referendo popular. Su resultado mostró la posibilidad de convivencia de diversos modelos que se confrontan dentro del llamado posconflicto:

Tanto en las instituciones como en el resto de la sociedad. La victoria del "No" en el plebiscito por la paz demostró que [...] su verdadero trasfondo fue ser una agenda nacional de oposición para proteger elementos sensibles del orden público y político sin querer rechazar o torpedear la paz de pleno, y aglomerar un conjunto de propuestas moduladoras de los procedimientos incluidos en distintas partes del acuerdo de paz sometido a plebiscito, que serían aceptados por los opositores solo tras modificaciones protectoras de la institucionalidad, que encontraron su forma de llegar al acuerdo mediante la apertura política que el resultado plebiscitario le brindó al proceso, al disponer al ejecutivo a recibir las propuesta de distintos sectores sociales (Arévalo \& Torrijos, 2016, pp. 146-147).

Sin embargo, la mayoría de la población sigue asociando "el concepto de seguridad con el de uso de la fuerza y con la coartación de libertades, tanto propias, como para los demás, queriendo buscar en la penalización jurídica y en la represión, respuestas a la inseguridad" (De León-Escribano, 2006), olvidando que pese al constante enfrentamiento militar no se ha alcanzado un estadio de seguridad normalizado a lo largo y ancho del territorio colombiano.

Los marcos de justicia transicional abarcan los procesos de transformación propuestos para lograr un escenario posconflictivo, propiciando cambios radicales sociopolíticos principalmente, debido a la finalización de un conflicto armado interno, y proyectando la paz (Uprimny, 2005).

Uprimny (2006) sostiene que dicha transformación hacia el posconflicto requiere lograr un equilibrio entre la justicia y la paz, que se encuentran en tensión permanente según las características particulares de cada uno de los actores, sujetos y acontecimientos. Es necesario investigar 
desde diversas perspectivas los procesos violatorios de los derechos humanos: la investigación selectiva o comprensiva; las funciones cuasijudiciales o el simple establecimiento de hechos; una composición nacional, o la colaboración de organizaciones internacionales - la OEA, la Comisión Interamericana de Derechos Humanos (CIDH) y la Corte Interamericana de Derechos Humanos (Corte IDH), la ONU y la CPI, entre otras- También puede asignárseles el uso de funciones como las recomendaciones públicas o los procesos de reintegración de los victimarios a la sociedad (Stahn, 2005).

\section{Minado/desminado y DH: antes y durante el Marco Jurídico para la Paz}

\section{Información mediática}

En 2011, previo al proceso del Marco Jurídico para la Paz, con la aprobación del proyecto de ley presentado por el gobierno, se informó que en Colombia existían en aquel entonces un poco más de 10200 víctimas por MAP, contabilizadas desde 1990. En contra de esta atroz táctica de guerra, prohibida igualmente por los Convenios de Ginebra y por sus protocolos adicionales, las organizaciones de la sociedad civil han realizado múltiples campañas de concienciación como las que mencionamos, entre las que se cuenta una de las más significativas, que alcanzó su institucionalización: la campaña Remángate, que se lleva a cabo todos los 4 de abril y que "invita a la población civil a 'remangarse' la bota de su pantalón en señal de protesta y como un gesto de solidaridad" con los mutilados y muertos por MAP (Gutiérrez, 2015).

En 2015, ya en curso el actual proceso de paz, una luz de esperanza que nos acerca a verdaderos visos de posconflicto es el plan piloto de DH que empezó labores en El Orejón, Briceño (Antioquia). Santos anunció la llegada de Colombia al escenario del posconflicto por dos hechos particulares: el reconocimiento y reparación de las víctimas mediante la Ley de Víctimas y Restitución de Tierras, y el DH (Orjuela, 2015d). La labor del DH se proyecta para un período mínimo de diez 
años, esto es, una esperanza de desminar el territorio nacional para el año 2025 aproximadamente, porque para 2021 será muy poco tiempo, así lo señaló el ministro del Posconflicto, el general en retiro Óscar Naranjo (ElColombiano, 2015). Las experiencias internacionales muestran que se siguen encontrando en los territorios europeos minas sembradas durante la Segunda Guerra Mundial, lo que puede hacer previsible la prórroga del plazo, para un desminado más efectivo.

Colombia está compuesta por 1123 municipios, en aproximadamente 650 de los cuales se han detectado minas. Este es uno de los grandes retos que se planteó el Marco Jurídico para la Paz. Es importante aclarar que El Orejón fue elegido el primer territorio para iniciar el DH porque allí hay más minas que habitantes y porque es una zona pequeña dónde adquirir grandes lecciones para el resto del territorio nacional. Desminar las áreas sembradas facilitará "la movilidad de la comunidad en riesgo y [permitirá] la restauración de derechos de las comunidades" (Orjuela, 2015d), sostuvo Dag Nylander, garante noruego. El programa piloto inició la descontaminación de artefactos explosivos en los departamentos de Antioquia y Meta, proceso que cuenta con la participación del Batallón de Desminado Humanitario (Bides), con amplia experiencia, y con miembros de las FARC (Orjuela, 2015a); no obstante, son los oficiales militares quienes con su entrenamiento son los llamados a descontaminar los territorios con la información que les proporcionan los exmiembros de las FARC, mientras estos, dentro del proceso, se van capacitando ya no en el minado, sino en el desminado. Humberto de la Calle Lombana, jefe de la delegación del gobierno de Colombia, sostuvo: "El acuerdo al que llegamos se está cumpliendo: las [FARC], en efecto, entregaron mapas precisos de la ubicación de las minas y contribuyeron activamente a delimitar las áreas minadas y con esa información iniciaremos la limpieza en la siguiente fase del proceso [...]” (Orjuela, 2015c, párr. 4).

Sin embargo, durante la implementación del plan han seguido explotando minas. Por ejemplo, luego de sus declaraciones, De la Calle se pronunció así mismo sobre el caso de Íngrid Guejía Guecio, una niña de solo 7 años que murió tras pisar una mina antipersona: “[...] Lombana [...] afirmó que es necesario acelerar el proceso de [DH] en el territorio nacional y exigió a las [FARC] no sembrar una mina más" 
(Orjuela, 2015b, párr. 1). Pero el 16 de julio de 2015, tras la muerte de un soldado durante el desarrollo del plan piloto para el DH y de la mutilación de otros miembros de la fuerza pública, el director de la AICMA, el general en retiro Rafael Colón, anunció la suspensión, por una semana, de la ejecución del plan, para restablecer los protocolos de seguridad en las actividades posteriores al fatídico hecho, que también dejó otros soldados con secuelas considerables. El general afirmó: "Estamos haciendo todas las indagaciones para hacer los ajustes necesarios y permitir que las operaciones acordadas continúen. Esta pausa técnica va a permitir reajustar las medidas y permitir la calidad para que tenga consonancia con los estándares de seguridad" (El Espectador, 2015, párr. 2).

\section{Entrevistas a informantes clave}

\section{Participación de la OEA ${ }^{24}$}

Las minas aparecieron en la escena de la humanidad cuando los ejércitos las crearon para reforzar el sector de la defensa de los Estados. Un arma militar efectiva, de bajo costo, capaz de detener el avance de tanques y otros equipos móviles de gran tamaño. Sin embargo, miembros de infantería del bando opositor aprendieron a desactivarlas y llevárselas. Requiriendo crear dispositivos antimanipulación para proteger las minas sembradas, creando una doctrina militar relativa, donde las guerras antitanque siempre estaban custodiadas de minas: la guerra de minas. La georreferenciación es fundamental. Saber dónde están las minas es la cuestión trascendente para el proceso actual, pues la geografía cambia y nos interesa medir qué tanto conocimiento tienen los miembros de las FARC sobre dónde están las minas, ya que es difícil saber quién sembró cada mina y muchos ya no recuerdan debido a los cambios de vegetación o al paso del tiempo, o porque están muertos. Antes de adentrarnos en el proyecto piloto, continuemos con los antecedentes de la OEA en cuanto al DH.

\footnotetext{
24 La información de este apartado se basa en la entrevista que, muy amablemente, el coronel (r) Guillermo Leal Abadía, jefe de misión del PAICMA de la OEA en Colombia, concedió a Diana Patricia Arias Henao en agosto de 2015.
} 
La OEA no conocía el DH. En realidad, el concepto ni existía y, obviamente, no existía tampoco el instrumento internacional. No existía esa palabra. Apareció entonces como una necesidad muy sentida, dada la cantidad de víctimas, especialmente civiles. Desde 1991, la OEA viene operando, aprendiendo de la temática y asistiendo a los países miembros. Los antecedentes retoman el Programa de Asistencia al Desminado en Centroamérica (PADCA), posterior a la solicitud de Costa Rica, Honduras, Guatemala y Nicaragua, cuyos territorios terminaron contaminados después de los conflictos armados presenciados en el siglo xx. En cuanto a la intervención, se sumaron entonces a conseguir experiencias internacionales exitosas, como las de Nicaragua (primer país libre de minas, 2005), Honduras, Costa Rica, Guatemala, El Salvador y Belice.

Después, Colombia, Ecuador y Perú solicitaron cooperación, y el programa se reestructuró en la AICMA, bajo directrices de la Asamblea General. La coordinación general está en manos del Departamento de Seguridad Multidimensional de la Secretaría General (Oficina de Acción Humanitaria contra las Minas) y recauda ayudas financieras. La Junta Interamericana de Defensa (JID) se encarga de aspectos técnicos como monitora en las zonas contaminadas. El Consejo Permanente de la OEA fomenta (2015), a través de la Comisión de Seguridad Hemisférica, la confianza y seguridad de las actividades. Para Colombia se diseñó la Agenda Estratégica de Cooperación, con cinco objetivos alineados con el Plan Nacional de Desarrollo, cuyo eje central rota sobre la cooperación y el incremento de efectos positivos en los sectores sociales por intervenir.

El Comité Científico y Técnico de la AICMA busca servir de enlace con la Dirección de Acción Integral contra Minas Antipersonal (DAICMA), que estudiaremos más adelante cuando compartamos la visión del gobierno.

\section{La AICMA}

Colombia, pese a sus altercados con los países vecinos, nunca minó sus fronteras soberanas y, dentro del territorio nacional, se caracterizó por el uso disminuido de MAP. Reportó 35 campos minados militares, 
la mayoría eran resguardos y bases de comunicaciones en zonas muy remotas. Sin embargo, la estrategia militar fue adoptada por actores armados ilegales que asumieron su uso como una necesidad en el conflicto asimétrico y debido a que las minas les permitían ejercer, sin mayores costos, un alto poder de intimidación, a través de los rastros de mutilación y muerte. Históricamente, el Ejército de Liberación Nacional (ELN) fue el primero que las sembró, y tras su afán mediático empezó a generar muertos relacionados con MAP. Luego, las FARC se sumaron a su uso.

Cuando la OEA conversó con el gobierno después de la adhesión al Tratado de Ottawa, el gobierno planteó que descontaminaría las áreas sembradas por el Ejército y que quienes sembraron las demás minas deberían asumir la responsabilidad del desminado. No obstante, la OEA ratificó que es el Estado colombiano quien tiene la plena responsabilidad y competencia a nivel territorial. Ante esto, el gobierno asumió el enorme reto de descontaminar, sin importar quién puso o no la mina. La misión es estrictamente humanitaria y se rige por los principios fundamentales de humanidad, neutralidad e imparcialidad, consagrados en la Resolución 46/182 de la AGNU (diciembre de 1991). En Colombia, el minado es artesanal. La primera intervención real de DH de la OEA tuvo lugar en el Bajo Grande, una zona abandonada por ocho años. Intervención real, pues, a consideración de la OEA, el proyecto piloto que se adelanta en Briceño no cumple los estándares internacionales para clasificarlo como DH.

Según la OEA, es riesgosa la politización de conceptos como el desminado militar y de emergencia, ya que se considera que la actividad de DH está completamente regulada tanto en lo exógeno como en lo endógeno. Así, no se cumplen cabalmente los principios ni los espacios humanitarios, ni mucho menos las especificaciones técnicas, puesto que el DH es un procedimiento que conlleva macroprocesos, subprocesos y procedimientos perfectamente detallados en Ottawa, la ONU y Ginebra. Colombia debe observar dicho marco normativo internacional para establecer sus estándares nacionales. Por debajo de dichas especificaciones están los procedimientos operacionales que cada operador del DH debe desarrollar, y cada tarea que se hace está completamente 
descrita; del mismo modo, debe contarse con sistemas de gestión de calidad, de gestión y de información.

En el artículo $2^{\circ}$ del Tratado de Ottawa está definido qué es una mina. No importa que sea artesanal, industrial, roja o amarilla, de plástico, de metal o de vidrio, ni que tenga uno o mil gramos de explosivos. En la norma referida en el numeral 1, se describe el alcance del concepto mina antipersona: "Se entiende toda mina concebida para que explosione por la presencia, la proximidad o el contacto de una persona, y que incapacite, hiera o mate a una o más personas. Las minas diseñadas para detonar por la presencia, la proximidad o el contacto de un vehículo, y no de una persona, que estén provistas de un dispositivo antimanipulación, no son consideradas minas antipersonal" (Organización de las Naciones Unidas, 1997).

No obstante, el proyecto piloto, denominado por el gobierno colombiano como de DH, es un acuerdo de muy buena factura, es un logro político. Una cosa es el DH y otra el posconflicto.

\section{La DAICMA ${ }^{25}$}

A modo de introducción, se presenta cuadro cronológico del sitio web de la DAICMA:

\section{Tabla 4. Cronología del desminado humanitario}

\begin{tabular}{|c|l|}
\hline 2001 & $\begin{array}{l}\text { Convención sobre la Prohibición de las Minas Antipersonal, artículo } 5^{\circ} \text { : } \\
\text { Colombia se compromete a destruir las zonas minadas antes del } 1^{\circ} \text { de marzo } \\
\text { de } 2011 .\end{array}$ \\
\hline $\mathbf{2 0 0 2}$ & $\begin{array}{l}\text { Ley } 759 \text { de 2002, artículo 18: Ministerio de Defensa Nacional, competente } \\
\text { para destruir zonas minadas. }\end{array}$ \\
\hline $\mathbf{2 0 0 5}$ & Inicia destrucción de zonas minadas en 35 bases militares. \\
\hline
\end{tabular}

(Continúa)

\footnotetext{
25 La información de este apartado proviene del gobierno, por el brigadier general Rafael Alfredo Colón Torres, líder de la DAICMA, del Ministerio del Posconflicto, Derechos Humanos y Seguridad, de la Presidencia de la República de Colombia; y por el coronel Germán Nicolás Pataquiva García, coordinador nacional de la DAICMA, brindada a las autoras, quienes también conversaron con Leandro Sánchez, que las introdujo en lo relativo a los sistemas de registro y de información electrónica de las víctimas de minas artesanales, y presenciaron reuniones de preacreditación de las OCDH.
} 


\begin{tabular}{|c|l|}
\hline 2009 & Se crea el Batallón de Ingenieros de DH N 60 - Bides - Disposición 29. \\
\hline 2011 & $\begin{array}{l}\text { Antes de cumplirse el plazo establecido por el Tratado de Ottawa, Colombia } \\
\text { cumplió con la destrucción de las minas en } 35 \text { bases militares. Colombia } \\
\text { solicitó y adquirió prórroga hasta } 2021 \text { para cumplir el artículo } 5^{\circ} \text { del Tratado } \\
\text { de Ottawa, debido al uso indiscriminado de MAP por grupos armados ilegales. } \\
\text { El artículo 9 de la Ley } 1421 \text { de } 2010 \text { autorizó el DH por organizaciones civiles } \\
\text { acreditadas. }\end{array}$ \\
\hline 2013 & Operaciones de The HALO Trust como la primera OCDH acreditada. \\
\hline 2014 & $\begin{array}{l}\text { Se crea la Agrupación de Explosivos y Desminado de la Infantería de Marina. } \\
\text { Disposición 41-2014. }\end{array}$ \\
\hline $\mathbf{2 0 1 5}$ & $\begin{array}{l}\text { Actualización del Plan Nacional de Desminado 2016-2018. } \\
\text { Actualización de los estándares nacionales de DH. }\end{array}$ \\
\hline
\end{tabular}

Fuente: sitio web de la DAICMA. ${ }^{26}$

Se informó al gobierno nacional acerca de la entrevista sostenida días atrás con la OEA y se indagó sobre la posición del Estado. Al respecto, el gobierno manifestó, en primera instancia, que, si bien las experiencias internacionales son muy valiosas para el Estado, las particularidades de estas no se acoplan a las necesidades colombianas, donde, por ejemplo, no hay minas industriales. El gobierno recalcó que quiere ser reconocido como el primer actor en dar pasos para lograr el posconflicto. "Para que el territorio deje de estar en conflicto debe desminarse, no puede desligarse el desminado del posconflicto, si queremos declararnos un país libre de minas", explicó.

En Colombia, el DH tiene muchos actores e intereses. Alrededor hay fuerzas económicas que se mueven para conseguir cooperación. El propósito del gobierno es poder alinear a todos los actores en una estrategia integral para el sector de la defensa, que se considera el sector trascendente, puesto que son los militares quienes poseen mayor conocimiento al respecto: 31 de 32 departamentos colombianos están minados y asegura que es consciente de que los estándares internacionales deben flexibilizarse en lo técnico, lo financiero,

\footnotetext{
26 http://www.accioncontraminas.gov.co/accion/desminado/Paginas/DesminadoHumanitario.aspx
} 
lo jurídico y lo político, para superar la mera extracción de minas y desarrollar una real acción integral en cuanto a los aspectos sociales que surgen en los territorios minados y en las comunidades desplazadas por las MAP, a fin de que regresen a sus territorios. Se trata de un desafío enorme que no puede limitarse por conceptos rígidos que no obedecen a necesidades particulares. Por ello, en agosto de 2015 el gobierno se encontraba modificando los estándares nacionales de acreditación, para integrar a más $\mathrm{OCDH},{ }^{27}$ ya que el gobierno no puede enfrentar solo el gigantesco desafío que implica declarar libre de minas a Colombia.

En agosto de 2015, se reportaron 560 municipios afectados; 189 con presencia de las FARC y 130 del ELN; el 66\% de las MAP están relacionadas con territorios de cultivos ilícitos. Hay zonas problemáticas en cuanto al acceso para desminar: comunidades indígenas, consejos comunitarios, áreas protegidas (parques nacionales) y las zonas de acceso geográfico riesgoso, entre los principales obstáculos para que dejemos de ser el segundo país con más víctimas civiles. Tan solo cuatro municipios colombianos han sido declarados libres de minas: San Carlos y San Francisco (Antioquia), El Dorado (Meta) y Zambrano (Bolívar). Actualmente, el DH es efectuado por las Fuerzas Militares con el Bides Antioquia, Caldas y Santander; con la Agrupación de Explosivos y Desminado de Infantería de Marina (AEDIM) en Bolívar; y con la OCDH The HALO Trust en otras zonas del departamento antioqueño (Dirección para la Acción Integral contra Minas Antipersonal, 2015). Las OCDH interesadas en atender las necesidades de la comunidad afectada por MAP, artefactos explosivos improvisados o municiones sin explotar, deberán manifestarlo por escrito a la DAICMA, llenando el anexo A del Estándar Nacional de Asignación de Tareas de DH.

El sistema de actualización de las víctimas es complejo y constante. No se contaba con un registro, sino con la información reportada por otras entidades, y se incluyeron víctimas diferentes de MAP que salen del registro, a la vez que se incorporan otras nuevas. También la

27 Decreto 3750 de 2011. Regula actividades de las OCDH en Colombia. 
DAICMA construyó una línea base a partir de datos publicados en la prensa. En 2015 contamos con información de primera mano e interactuamos en línea directamente con la víctima o sus familiares, gracias al sistema suizo IMSMA (Information Management System for Mine Action).

El proyecto piloto se concentró en un territorio pequeño para luego asumir retos territoriales más complejos. Si bien la georreferenciación es trascendental, más lo son los cambios sociales que se han presentado en los territorios contaminados, y en este contexto se debe mencionar la gestión de acción integral del gobierno colombiano, que cuenta con las siguientes líneas estratégicas: incrementar la capacidad de desminado y dar respuesta rápida; fortalecer la coordinación interinstitucional, para la regulación de los actores del AICMA; fortalecer la presencia territorial, para la construcción de planes AICMA, con la participación de comunidades y autoridades locales; y consolidar un sistema de gestión de información oportuno, claro y robusto, proveniente de los territorios. En cuanto a las técnicas del desminado, este puede ser manual (desminador) o mecánico (control remoto y equipos). Lo anterior bajo el estricto cumplimiento de los principios: enfoque territorial y diferencial, integridad, respuesta rápida, participación y flexibilidad e innovación para garantizar debidamente la asistencia, atención, reparación, todo esto en un marco de ayuda humanitaria, mediante la aplicación de medidas preventivas relativas a la educación en el riesgo de MAP, y la difusión a través de medios de comunicación.

\section{Conclusiones}

Hemos observado nuestro objeto de estudio: minado/desminado humanitario desde un enfoque jurídico-político durante la aplicación del programa piloto previo a la finalización del Acuerdo de Paz entre las FARC y el gobierno colombiano. La tipificación temática es absolutamente interméstica, es decir, conlleva elementos endógenos y exógenos, los cuales se armonizan, tanto a nivel jurídico como a nivel teórico, en la defensa de los estándares de la seguridad ciudadana, bien sea en el marco de una guerra clásica entre Estados soberanos 
o bien se trate de un conflicto armado; lamentablemente, debe ser efectivamente declarado y reconocido como tal para que la subsidiariedad penal entre en escena.

A través de la metodología empleada fue posible vislumbrar que muchos de los conceptos jurídicos relativos a la protección de los derechos fundamentales son conceptos que surgen desde contextos precedidos de violencia sistémica, y mediante meras decisiones políticas. Dicha funcionalidad procrea la alternatividad jurídica desde fuentes no formales de derecho. Por ello, no obstante, no deja de ratificarse la subsidiariedad penal y sus efectos erga omnes, generados en la coercitividad jurídica ejercida sobre las actividades de uso de artefactos explosivos enterrados.

Esta práctica generalizada en el conflicto armado colombiano, aprendida de las acciones militares engendradas en guerras clásicas, pero perfiladas en marcos teóricos aún no armonizados a través de fuentes indefectibles doctrinarias y contemporáneas, conlleva flexibilizaciones operacionales en cuanto a la falta de teorización jurídica, por ejemplo, la figura del posconflicto.

No existe claramente una justificación doctrinal homogeneizada ni relevante que adhiera el concepto de posconflicto dentro de las materias del derecho internacional penal. Sin embargo, la subjetividad doctrinal y sus respectivos contextos de ocurrencia e influencias hereditarias son armonizadas por medio del recorrido jurisprudencial realizado en la especificidad de la práctica del minado/desminado humanitario en Colombia. Incluso, yendo más allá, para un gran sector doctrinal, el posconflicto no es siquiera un concepto contentivo del derecho internacional.

No obstante, la idea no es perdernos en las diferencias doctrinales relativas a conceptos de origen más político que jurídico, pues, como lo que ocurre con la misma definición de terrorismo, no existe una teorización más confiable, sin embargo, existen varias subclasificaciones de este, como el ciberterrorismo, narcoterrorismo y terrorismo de Estado. Incluso podríamos zanjar las diferencias con la creación del Ministerio del Posconflicto. Si bien es posible justificar 
la creación doctrinal del posconflicto a través de la creación de marcos alternativos de justicia especial, que abarcan varios sectores, como lo ocurrido con los tribunales de Núremberg y de Tokio, una vez concluida la Segunda Guerra Mundial, también podemos partir del simple significado de considerarlo como la etapa posterior a la superación parcial o total de un conflicto.

Entonces, no podemos considerar a Colombia como un escenario de posconflicto total, sino una aproximación a un posconflicto parcial entre un actor armado ilegal y un sujeto legal: las FARC y el Estado colombiano, respectivamente, lo que está direccionando al país a la construcción de una paz negativa, es decir, al cese y la ausencia de violencia entre los firmantes. Sin embargo, el plan piloto del desminado humanitario trasciende la paz negativa, puesto que, más allá de la ausencia de conflicto, se prevé una construcción conjunta entre los combatientes, que ya antes de finalizar los acuerdos de paz se puso en marcha, incluso sin mediar un escenario posconflictual.

Ahora bien, una de las complicaciones de desintoxicar el territorio colombiano de artefactos explosivos es que en el suelo cafetero existen diversos tipos de minas artesanales, muchas veces construidas sin ningún material metálico, que dificulta su detección y consecuente extracción. Igualmente, son elevados los costos del desminado, puesto que fabricar una mina cuesta un dólar; sin embargo, hallarlas y desactivarlas cuesta hasta mil veces más, incluso la vida de quienes realizan esta heroica labor. "Por lo menos 7000 han caído en ellas en los últimos 15 años, de los cuales 1400 han muerto" (Ruiz, 2015).

Independientemente de lo anterior, en el marco del posconflicto y las labores de desminado, Colombia debe prever sanciones penales en cuanto al empleo de MAP, a fin de cumplir con los estándares internacionales aplicables y reconocidos por el país. De no generarse responsabilidad penal por el minado en Colombia, cabría la competencia de la CPI en esta materia, dado que se configuran delitos de lesa humanidad y crímenes de guerra derivados del empleo de MAP. 


\section{Referencias}

(2 de marzo de 2009). ¿Qué es la Convención de Ottawa y en qué consistirá la Conferencia de Revisión del Tratado? El Tiempo. Recuperado de http://www.eltiempo.com/archivo/documento/CMS-4851188 (2 de diciembre de 2014). Dura advertencia de la Corte Penal Internacional a Colombia. El Tiempo. Recuperado de http://www.eltiempo.com/ politica/justicia/dura-advertencia-de-la-corte-penal-internacionala-colombia/14920616

(7 de marzo de 2015). El desminado duraría 10 años: Óscar Naranjo. El Colombiano. Recuperado de http://www.elcolombiano.com/el-desminado-duraria-10-anos-oscar-naranjo-ND1445539

(16 de julio de 2015). Realizarán ajustes necesarios a plan de desminado tras muerte de soldado. El Espectador. Recuperado de http://www. elespectador.com/noticias/judicial/realizaran-ajustes-necesariosplan-de-desminado-tras-mu-articulo-573018

Arévalo, W. \& Torrijos, V. (2016). Del plebiscito a la reforma: movimientos políticos y cambios fundamentales a los acuerdos de paz en Colombia tras la victoria del no en el plebiscito de 2016. Revista Política y Estrategia, (129), 146-147. https://doi.org/10.26797/rpye.v0i129.73

Azpuru, D., Blanco, L., Córdova, R., Loya, N., Ramos, C. \& Zapata, A. (2007). Construyendo la democracia en sociedades posconflicto. Guatemala y El Salvador, un enfoque comparado. Guatemala: F\&G.

Bass, G. (2004). Jus post bellum. Philosophy \& Public Affairs, 32(4), 384-412. https://doi.org/10.1111/j.1088-4963.2004.00019.x

Boutros-Ghali, B. (1992). An agenda forpeace. Nueva York: United Nations. Chetail, V. (Ed.). (2009). Post-conflict peacebuilding: a lexicon. Nueva York: Oxford University Press.

Colombia, Corte Constitucional. Sentencia C-991 de 2000. M. P.: Álvaro Tafur. Colombia, Corte Constitucional. Sentencia C-290 de 2012. M. P.: Humberto Sierra.

Colombia, Ministerio de Defensa Nacional. Decreto 3750 de 2011.

Colombia, Vicepresidencia de la República. (2012). Glosario nacional básico general de términos de Acción Integral contra Minas Antipersonal. Recuperado de http://www.accioncontraminas.gov.co/prensa/Documents/ glosario_terminos_accion_contra_minas.pdf

Colombia. Constitución Politica (1991). 


\section{6 / Diana Patricia Arias - Juanita María Ospina Perdomo}

Comité Internacional de la Cruz Roja. (1980). Protocolo sobre probibiciones o restricciones del empleo de minas, armas trampa y otros artefactos (Protocolo II) (CCWPII). Ginebra. Recuperado de https://www.icrc.org/spa/resources/documents/misc/5tdl6e.htm

Comité Internacional de la Cruz Roja. (1996). Protocolo sobre probibiciones o restricciones del empleo de minas, armas trampa y otros artefactos según fue enmendado el 3 de mayo de 1996 (Protocolo II según fue enmendado el 3 de mayo de 1996). Ottawa. Recuperado de https://www.icrc.org/spa/resources/documents/misc/treaty-1980-cccw-protocol-2-amended-1996-5tdl6g.htm

Comité Internacional de la Cruz Roja. (2008). Los crimenes de guerra según el Estatuto de Roma de la Corte Penal Internacional y su base en el derecho internacional humanitario. Cuadro comparativo. Ginebra: Servicio de Asesoramiento en Derecho Internacional Humanitario. Recuperado de https://www.icrc.org/spa/assets/files/other/sp_-_crimenes_de_guerra_cuadro_comparativo.pdf

Consejo Permanente de la Organización de los Estados Americanos/ Comisión de Seguridad Hemisférica. (2015). Acción contra las minas antipersonal. Programa de Acción Integral contra Minas Antipersonal (AICMA). Recuperado de http://www.oas.org/csh/spanish/desmAICMA.asp

Corte Penal Internacional. (1998). Estatuto de Roma de la Corte Penal Internacional. Recuperado de http://www.un.org/spanish/law/icc/statute/ spanish/rome_statute(s).pdf

De León-Escribano, C. (2006). Armas pequeñas y desarrollo en sociedades post conficto. Guatemala: Instituto de Enseñanza para el Desarrollo Sostenible. Recuperado de http://iepades.com/wp-content/uploads/2013/10/ pv_armas_postconflicto.pdf

DiMeglio, R. (2005). The evolution of the just war tradition: defining jus post bellum. Mil. L. Rev., 186, 116. https://doi.org/10.1017IS02602105 10000434

Dirección para la Acción Integral contra Minas Antipersonal. (2015). ¿Quiénes somos? Recuperado de http://www.accioncontraminas.gov. co/direccion/Paginas/Quienes-Somos.aspx

Dirección para la Acción Integral contra Minas Antipersonal. (2015). Depuración registros. Recuperado de http://www.accioncontraminas.gov.co/ estadisticas/Paginas/depuracion-registros.aspx 
Dirección para la Acción Integral contra Minas Antipersonal. (2015). Bitácora de víctimas civiles 2015. Recuperado de http:/ / www.accioncontraminas. gov.co/estadisticas/Paginas/Bitacora-de-victimas.aspx

Galtung, J. (1975). Three approaches to peace: peacekeeping, peacemaking and peacebuilding. En Peace, war and defence. Essays in peace research. 2 (pp. 282-304). Copenhague: Christian Heljers.

Garzón, J., Parra, A. \& Pineda, A. (2003). Elposconflicto en Colombia: coordenadas para la paz. (Trabajo de grado en Derecho, Pontificia Universidad Javeriana, Bogotá, Colombia).

Gutiérrez, S. (3 de abril de 2015). ¡Remángate! en contra de las minas antipersonal en Santander. Radio Nacional de Colombia. Recuperado de http://www.radionacional.co/noticia/remangate-en-contra-de-lasminas-antipersonal-en-santander

International Campaign to Ban Landmines. (s. f. a). Arguments for the ban. Recuperado de http://www.icbl.org/en-gb/problem/arguments-forthe-ban.aspx

International Campaign to Ban Landmines. (s. f. b). A history of landmines. Recuperado de http://www.icbl.org/en-gb/problem/a-history-oflandmines.aspx

Kreutz, J. (2010). How and when armed conflicts end: introducing the UCDP conflict termination dataset. Journal of Peace Research, 47, (2), 243-250. https:/ / doi.org/10.1177/0022343309353108

Maslen, S. \& Herby, P. (1998). Prohibición internacional de las minas antipersonal. Historial y negociación del "Tratado de Ottawa". Revista Internacional de la Cruz Roja, 23(148), 747-757. Recuperado de https: / / www.icrc.org/es/doc/resources/documents/misc/5tdmng.htm

Molano-Rojas, A. (Ed.). (2015). El posconflicto en Colombia: reflexiones y propuestas para recorrer la transición. Bogotá: Fundación Konrad Adenauer Colombia-Instituto de Ciencia Política Hernán Echavarría Olózaga. Organización de las Naciones Unidas. (1997). Convención sobre la probibición del empleo, almacenamiento, producción y transferencia de minas antipersonales y sobre su destrucción. Oslo. Recuperado de http://www.unog. ch/80256EDD006B8954/(httpAssets)/B9A95DEB6541532BC 12571C7002E56DA/\$file/Convencion_d_Ottawa_Espanol.pdf

Orjuela, M. (8 de mayo de 2015a). Gobierno y FARC avanzan en implementación del plan piloto de desminado: De la Calle. Radio Nacional de Colombia. Recuperado de http://www.radionacional.co/noticia/ 
gobierno-y-farc-avanzan-en-implementacion-del-plan-piloto-dedesminado-de-la-calle

Orjuela, M. (21 de mayo de 2015b). Humberto de la Calle pide acelerar proceso de desminado. Radio Nacional de Colombia. Recuperado de http://www.radionacional.co/noticia/humberto-de-la-calle-pideacelerar-proceso-de-desminado

Orjuela, M. (29 de mayo de 2015c). Así avanza la primera fase de desminado entre gobierno y las FARC. Radio Nacional de Colombia. Recuperado de http://www.radionacional.co/noticia/primera-fase-de-desminadoavanzara-en-4-areas-peligrosas-de-12-mil-metros-cuadrados

Orjuela, M. (17 de junio de 2015d). Desminado y Ley de Víctimas hacen parte de la entrada del posconflicto: Santos. Radio Nacional de Colombia. Recuperado de http://www.radionacional.co/noticia/desminado-yley-de-victimas-hacen-parte-de-la-entrada-del-posconflicto-santos

Pérez, T. (2011). Conflicto y posconflicto en Colombia: una mirada a la política de seguridad democrática. Magistro, 5(10), 129-150.

Rettberg, A. (2003). Diseñar el futuro: una revisión de los dilemas de la construcción de paz para el posconflicto. Revista de Estudios Sociales, (15), 15-28. https:// doi.org/10.7440/res15.2003.01

Rettberg, A. (2012). Construcción de paz en Colombia: contexto y balance. En A. Rettberg (Comp.), Construcción de paz en Colombia (pp. 3-50). Bogotá: Ediciones Uniandes. https://doi.org/10.7440/2012.24

Ruiz, M. (20 de junio de 2015). Vidas paralelas. Semana. Recuperado de http://www.semana.com/nacion/articulo/las-vidas-paralelas-derafael-colon-pastor-alape/432061-3

Stahn, C. (2005). La geometría de la justicia transicional: opciones de diseño institucional. En A. Rettberg (Comp.), Entre el perdón y el paredón: preguntas y dilemas de la justicia transicional (pp. 81-142). Bogotá: Universidad de los Andes.

Stahn, C. (2006). 'Jus ad bellum', 'jus in bello'... 'jus post bellum'? Rethinking the conception of the law of armed force. The European Journal of International Law, 17(5), 921-943. https://doi.org/10.1093/ejil/chl037

Ugarriza, J. (2013). La dimensión política del postconflicto: discusiones conceptuales y avances empíricos. Colombia Internacional, (77), 141-176. https://doi.org/10.7440/colombiaint77.2013.06

Universidad del Rosario. (s. f.). Experimentos de reconciliación politica en Colombia. Grupo de Investigación en Derechos Humanos. Recuperado de http:// 
www.urosario.edu.co/jurisprudencia/jurisprudencia-reconciliacion/ ur/Postconflicto/

Uprimny, R. (2005). ¿justicia transicional sin transición? Reflexiones sobre verdad, justicia y reparación en Colombia. Manuscrito sin corregir, Recuperado de http://www.djs.org.co/pdf/investigaciones/justiciaTransicional.pdf Uprimny, R. (2006). Las enseñanzas del análisis comparado: procesos transicionales, formas de justicia transicional y el caso colombiano. En R. Uprimny, M. Saffon, C. Botero \& E. Restrepo, ¿Justicia transicional sin transición? Verdad, justicia y reparación para Colombia (pp. 17-44). Bogotá: Centro de Estudios de Derecho, Justicia y Sociedad. Recuperado de https://www.minjusticia.gov.co/Portals/0/Foros\%20Justicia\%20 Transicional/LIBRO\%20J.TRANS..pdf

Valladares, P. (Comp.). (2003). Derecho internacional humanitario y temas de áreas vinculadas. En Leccionesy Ensayos $N^{\circ} 78$ (pp. 297-310). Buenos Aires: LexisNexis Abeledo-Perrot. Recuperado de https://www.icrc. org/spa/resources/documents/misc/63pmbc.htm 